九州大学学術情報リポジトリ

Kyushu University Institutional Repository

\title{
A phylogenie consideration of Chrysomelinae based on immature stages of Japanese species (Coleoptera)
}

Kimoto, Shinsaku

Hikosan biological laboratory, Department of Agriculture, Kyushu University

https://doi.org/10.5109/22694

出版情報 : 九州大学大学院農学研究院紀要. 12 (2)，pp.67-88，1962-10. Kyushu University バージョン：

権利関係 : 
Journal of the Faculty of Agriculture, Kyushu University, Vol. 12, No. 2

October 30,1962

\title{
A phylogenic consideration of Chrysomelinae based on immature stages of Japanese species (Coleoptera) ${ }^{*}$
}

\author{
Shinsaku Kiмoтo
}

\section{INTRODUCTION}

On the comparative morphologies of the early stages of Japanese Chrysomelinae, only some fragmental contributions have been made. On the European species two important studies have been made by Paterson (1930--31) and Hennig (1938). The former was based on species on England and the latter on German ones. These two reports suggest important taxonomic knowledge. Unfortunately, taxonomic studies based on morphology of the early stages have been neglected. I believe that the taxonomic value of larval and pupal morphology of Chrysomelinae must be further appraised.

In this paper, I describe the early stages of 17 species of Japanese Chrysomelinae and discuss the nomenclature of the setae and tubercles, based on my opinion that setal and tubercular morphology must be dynamically recognized through the changes in the course of the larval growth. I also report some information for phylogenic classification of the Chrysomelinae, based on larval and pupal morphology, comparing it with contributions made by Paterson, Hennig and other isolated contributions made by many Japanese and foreign entomologists.

But, I recoginize that this paper is still incomplete, because it cannot be said that the morphology of world species of the early stages of Chrysomelinae has been satisfactorily studied. Moreover, my studies are based on materials limited to the Japanese fauna. It is hoped, however, that these studies will serve as an initiative to further research on the subject.

Before going further I wish to express my hearty thanks to the iate Dr. Teiso Esaki, Prof. Keizô Yasumatsu and Prof. Yoshihiro Hirashima

* Contribution Ser. 2, No. 144, Entomological Laboratory, Kyushu University. (Studies on immature stages of Japanese Chrysomelinae 1) 
of Kyushu University, for their kind guidance and encouragement; also to Prof. Michio Chûjô of Kagawa University, for his valuable advice on taxonomy of Chrysomelinae; further to Prof. Shôichi Miyamoto of Kyushu University, Prof. Tetsuo Takara of the University of the Ryukyus, Dr. Kazuyoshi Kurosa of Tokyo, Mr. Y. Miyake of Fukuoka, Mr. Masao Ohno of Tôyô University, Dr. Katsura Morimoto of the Forestry Experiment Station, Ministry of Argiculture \& Forestry and Mr. Manabu Iwatsuki of Aichi, for their kind help to present studies.

\section{Materials}

In this study, the following species or subspecies were used:

1. Chrysolina aurichalcea (Mannerheim, 1825)

2. Chrysolina exanthematica (Wiedemann, 1821)

3. Gonioctena (Brachyphytodecta) rubripennis Baly, 1862

4. Gonioctena (Gonioctena) japonica Chûjô et Kimoto, 1960

5. Potaninia cyrtonoides (Jacoby, 1885)

6. Phola octodecimguttata (Fabricius, 1775)

7. Phaedon brassicae Baly, 1874

8. Phaedon nigritus (Chûjo, 1951)

9. Gastrophysa atrocyanea Motschulsky, 1860

10. Chrysomela vigintipunctała (Scopoli, 1763)

11. Chrysomela populi Linné, 1758

12. Linaeidea aenea insularis (Chûjo, 1940)

13. Linacidea aenea (Linné, 1758)

14. Plagiodera versicola (Laichart, 1781)

15. Gastrolina depressa Baly, 1859

16. Gastrolina peltoides (Gebler, 1832)

17. Gastrolinoides japonica (Harold, 1877)

Among the above listed 17 species or subspecies, nos. 3, 5, 9, 10 and 14 were bred from oviposition to emergence of the adults at Fukuoka City. Of these five species, breedings of nos. 3, 9, 10 and 14 were started by the adults collected at Fukuoka City, and breeding of no. 5 was started by the adults collected on Mt. Hiko-san.

Of the eight species, nos. $2,4,7,11,13,15,16$ and $17, \mathrm{I}$ bred the younger larvae to emergence of adults. Young larvae of nos. 2 and 7 were collected in Fukuoka City, and the first instar larvae of no. 11, were collected on Mt. Hiko-san in Fukuoka Pref. These larvae were bred to emergence of adults, in Fukuoka City. Mature larvae of no. 4 were collected on Mt. Hôki-Daisen in Tottori Pref,, at Nikko in Tochigi Pref. and at Masutomi in Yamanashi Pref., of no. 13 on Mt. Daisetsu-zan in Hokkaido, of no. 15 at Akan Nat. Park in Hokkaido, and at Nikkoin Tochigi Pref., of no. 16 at Nikko in Tochigi Pref., and of no. 17 on Mt. Hôki-Daisen in Tottori Pref. Some of these larvae were bred in Fukuoka City to emergence of adults and the others were bred during 
travels.

I had no chance to breed larvae of nos. 1, 6, 8 and 12. But larvae of these were presented to me by many entomologists. No. 1 was collected by Dr. K. Kurosa at Saiki City in Oita Pref., no. 6 by Prof. S. Miyamoto and Prof. T. Takara on the Tokara Is. and Ryukyu Is., no. 8 by Mr. M. Miyatake at Matsuyama City in Ehime Pref., and no. 12 by Dr. K. Morimoto at Makiyama in Kôchi Pref. I also have vast numbers of other alcoholic specimens which were presented by Dr. K. Kurosa, Mr. Y. Miyake, Dr. K. Morimoto and Mr. M. Iwatsuki.

\section{HistoricAl REVIEWS OF NOMENCLATURE ON IAARVAL TUBERCLES AND SETAE OF CHRYSOMELINAE}

The first worker who found the taxonomic importance of tubercles and setae of Chrysomelid-beetles was Sanderson (1902), who showed the notation tubercles of the most generalized Chrysomelid-Iarvae (Fig. 1).
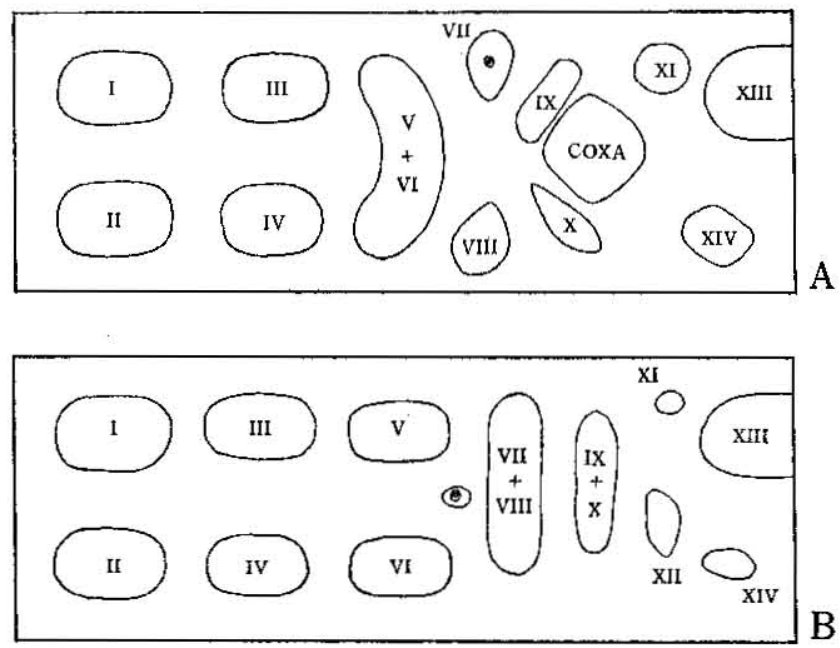

Fig. 1. Hypothetical segments in Chrysomelid larvae according to Sanderson (1902). A. Mesothorax. B. Abdominal segments I-VII.

He showed diagram of notation tubercles but did not give any practical apprication to the tubercles of the species. But $I$ think that his nomenclature influenced Paterson's nomenclature.

Paterson (1931) proposed his hypothetical type of setal and tubercular form based on the following opinion (fig. 2), that is, each tubercle originated by chitinization of integument at the base of a single seta, and consequently in a primitive condition every segment of the body would be similarly furnished with two rows of setae, each of which 
would be located on a small round tubercle. Further, he divided the tubercles into six groups, that is dorsal tubercles, dorso-lateral tubercles, subspiracular tubercles, pleural tubercles, ventro-lateral tubercles and ventral tubercles. In a typical form, he thought that dorsal tubercles had four setae, dorso-lateral tubercles had four setae, subspiracular tubercles had two setae, pleural tubercles had two setae, ventro-lateral tubercles had two setae, and ventral tubercles had two setae, and then tried to explain all of the setal forms that occurred in larvae of Chrysomelidae. Later his nomenclature was ciriticized by Hennig based on knowledge of larvae of German Chrysomelinae.

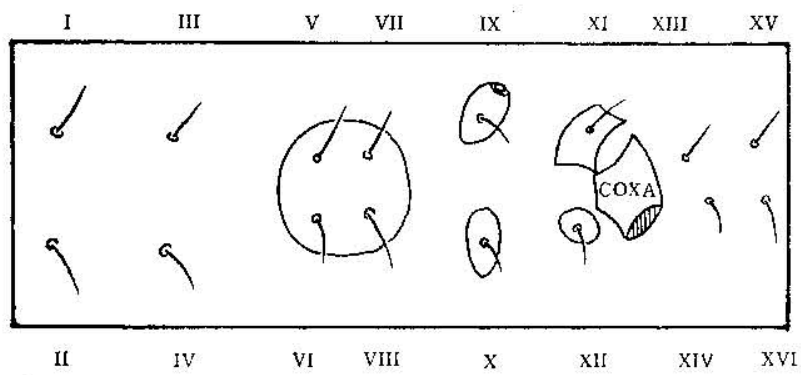

Fig. 2 Hypothetical segments in Chrysomeidae larvae according to Paterson (1931).

Hennig (1938) criticized Paterson's nomenclature. His studies were done on German species of Chrysomelinae, and his materials included species of Chrysochloa Hope (=Oreina Chevrolat), Colaphus Redtenbacher (=Colaphellus Weise), Scleophaedon Weise, Entomoscelis Chevrolat and Phytodecta Kirby ( $=$ Gonioctena Chevrolat), which were not treated in Paterson's studies. He divided Chrysomelinae into two large groups, namely oligochaeten Larvengruppe and polychaeten Larvengruppe. ${ }^{*}$ In oligochaeten Larvengruppe, species of Plagiodera Redtenbacher, Melasoma Stephens (=Chrysomela Linné), Phyllodecta Kirby (=Phratora Chevrolat), Hydrothassa Thomson, Prasocuris Latreille, Phaedon Latreille and Gastroidea Hope (=Gastrophysa Chevrolat) were included. On the other hand, in polychaeten Larvengruppe, species of Chrysochloa Hope (=Oreina Chevrolat), Chrysolina Motschulsky, Leptinotarsa Stal (=Polygramma Chevrolat), Colaphellus Weise, Phytodecta Kirby (-Gonioctena Chevrolat) and Scleophaedon Weise were included. As a result of his studies on the polychaeten Larvengruppe, he concluded that although

* According to Hennig's descriptions, species of oligochacten Larvengruppe were characterized by generally smaller number of setae and with a pair of glandulife. rous tubercles situated on meso- and metathorax and on the first to the seventh abdominal segments. The species of polychaten Larvengruppe were characterized by generally larger number of setae and without above mentioned glanduliferous tubercles. 
Paterson's nomenclature was proposed for the whole family Chrysomelidae, his nomenclature, in fact, was only applicable to oligochaeten Larvengruppe of Chrysomelinae. But in spite of this criticism, he did not propose a new system of nomenclature.

\section{CRITICISM OF THE PREVIOUS NOMENCLATURE OF LARVAL SETAE}

As I expressed in previous paragraphs, the most important opinions of Paterson (1931) were that each tubercle originated by chitinization of integument at the base of a single seta, and that each of the setae would be located on the small round tubercles. And also he said the setal arrangement is remarkably constant throughout larval life, and few, if any, secondary setae are developed in the second and the third instar, and tried to explain any kind of setal forms that occurred in Chrysomelidae as a variant form from this typical form. Later, his nomenclature was criticized by Hennig (1938), who stated that although Paterson's nomenclature of setae was given for the whole Chrysomelidae, his nomenclature was applicable to a group of Chrysomelinae (oligochaeten Larvengruppe).

Hennig's criticism was that between polichaeten Larvengruppe and oligochaeten Larvengruppe homologous relations of tubercles were clearly recognized but in polychaetan Larvengruppe extremely vast numbers of setae were located on a single tubercle, and so it is impossible to explain homologies of these larval setae by Paterson's nomenclature. The greatest reason for Hennig's criticism of Paterson's nomenclature is that Paterson did not examine the larvae of polychaeten Larvengruppe, for instance Gonioctena, Entomoscelis, and so on.

As I mentioned above, Hennig clearly pointed out the weak points of Paterson's nomenclature on the last instar larvae. But I differ with Hennig's opinion on the larval setae of polychaeten Larvengruppe. As Hennig stated, in the last larval instar, the larvae of polychaeten Larvengruppe is characteristic in having so many setae which may distinguish it from oligochaeten Larvengruppe. On the other hand, in the first larval instar it is hardly said that the larvae of polychaten Larvengruppe have vast numbers of setae as much to distinguish it, comparing with oligochaeten Larvengruppe, and these setae increase their number in the course of the growth, and in the last larval instar, these setae become to distinguish the group from oligochaeten Larvengruppe. In other words, differences between oligochaeten and polychaeten Larvengruppe are explained as a difference of setal change in the course of the growth.

As I mentioned above, if we limit the applications of Paterson's 
nomenclature on larval setae to the first instar larvae, his nomenclature will be somewhat applicable to the larval setae of Chrysomelid-beetles. On the other hand, even if we limit the applications of the nomenclature within the first instar larvae, this would still hold some difficulties on the studies of setal homology which was already pointed out by Fracker (1951). That is: 1, absence of intermediate stages between radically different conditions, and 2 , the lack of developmental series. But these are common problems in the studies of larval setae of insects, occurring both in Lepidoptera and Coleoptere. In addition to the difficulties of studies, it is pointed out in Lepidoptera also by Fracker (1915), that when the tubercles are fused, the setae on these tubercles show tendency to vary in number, and this tendency is also recognized in Chrysomelid-beetles. In Chrysomelid-larvae, all setae locate on tubercles, and many of these tubercles are fused together in most of the species. In the Chrysomelidae, especially Chrysomelinae, variation of setal number based on fusion of tubercles is a very serious problem. In many cases, if we try to do research on setal homologies, we would find that homology of setae locating in the fused tubercles is impossible. Strictly speaking, on research of setal homology in the Chrysomelid-beetles, the only possible conclusion would be that all of the setae locating on a tubercle is homologous to the whole of the setae locating on another homologous tubercle.

On the other hand, tubercles which surround the setae seem to have very important taxonomic value in the Chrysomelid-larvae. Generally, these tubercles are of relatively large size, and in the first larval instar the variations are very few, and so I think that studies of these homologous relations of the larval tubercles are more accurately and easily performed than these of the larval setae. Therefore, I appraise highly the value of the tubercles as a taxonomic characteristic and also think that it is necessary to establish the nomenclature of the tubercles based on homology.

But my opinions do not absolutely mean that I doubt the taxonomic values of larval setae. I recognize that it is the tubercles that are originated by the sclerotization of the integument at the base of a single seta, as Paterson pointed out in his paper. I think that each seta has taxonomic importance, so that each tubercle being originated by larval seta has taxonomic importance. I recognize that larval setae have much taxonomic importance and the tubercles are secondarily originated by the sclerotization of the base of setae. But, as I mentioned above, the tubercles of Chrysomelid-larvae are in many cases fused together, and variations of the setal number based on this fusion of the tubercles are very extensive, so that $I$ wish to use the tubercles as useful taxonomic characteristics, which are secondarily originated by the setae, but the arrangement of tubercles also has taxonomic 
importance and moreover these homologous relations are more easily recognized than these of the setae.

\section{NEW NOMENCLATURE}

As I expressed in Chapter IV, I believe that it is impossible to do research on the homology of larval setae of Chrysomelinae, except on the homologous tubercles on which setae are locating. Therefore, it is very important to settle the tubercular nomenclature based on homology when we try to recognize the tubercular forms based upon their phylogeny. In Chrysomelid-larvae, the body wall may be divided into five parts. These are Dorsal part, Dorso-lateral part, Epipleural part, Pleural part and Sternal part. I name the tubercles situated in each of these parts as Dorsal tubercle (D), Dorso-lateral tubercle (DL), Epipleural tubercle (EP), Pleural tubercle (P) and Sternal tubercle (S).

In Chrysomelid-larvae, there are many kinds of tubercular changes in the course of the larval growth. I classify the tubercles into two categories. I name tubercles which exist from the first instar larvae as Primary tubercle and also name the tubercles which appear secondarily in the course of larval growth as Secondary tubercle. But some of these tubercles always appear on the same place and have taxonomic value. I give these tubercle names based on homology.

\section{A) Primary tubercle}

Dorsal region: In this part, sometimes these tubercles are divided into anterior and posterior tubercles. I name these tubercles as Dorsoanterior tubercle (Da), and Dorso-posterior tubercle (Dp). Sometimes, these tubercles are divided into interior and exterior tubercles. I name these tubercles as Dorso-interior tubercle (Di) and Dorso-exterior tubercle (De). (Plate 1: 1, 6, 8)

Dorso-lateral region: In this part, sometimes tubercles are divided into anterior and posterior tubercles. I name these tubercles as (DLa) and (DLp). And sometimes, they are divided into interior and exterior tubercles. I name (DLi) and (DLe). (Plate 1: 1, 6, 8)

Epipleural region: On the abdominal segment, there is a tubercle, which I call Epipleural tubercle (EP). But, in the thoracic segment, it is divided into 2 tubercles. I name them as (EPa) and (EPp)*. (Plate 1: 2, 3)

Pleural region: In this part, there is always a tubercle. I name it as Pleural tubercle (P). $\dagger$ (Plate 1:2,3)

* According to Peterson's nomenclature, spiracular tubercle and (EPa) are treated as the tubercles belonging to the epipleural region. But, Böving (1926) treated them as the tubercles of alar region.

$\uparrow$ According to Paterson's nomenclature, there are two pleural tubercles. But, I think that the anterior pair of the tubercles is trochantin. Böving (1928) treated these tubercles as prephypopleural sclerite ( $=$ episternum) and postphypopleural sclerite (=epimeron). 
Sternal region: In this part, there are typically three tubercles. I name them as Eusternal tubercle (ES), Sternellar tubercle (SS) and Parasternal tubercle (PS). On the abdominal segments, sometimes (PS) is divided into two tubercles. These are (PSi) and (PSe). (Plate 1:2,3)

B) Secondary tubercle.

In the oligochaeten Larvengruppe, secondary tubercles appear on the dorsal and the sternal regions.

Dorsal region: In this part, sometimes secondary tubercles appear on antero-exterior part of the tubercle (D). I name these tubercles as (ad 1). (Plate 1: 9)

Sternal region: On the abdomenal segment, a secondary tubercle always appears on antero-exterior part of the tubercle (ES). I name the tubercle as (as 1). (Plate 1:9)

The seta named by Hennig (1938) as seta (XVII) is homologous to the seta located on secondary tubercle (as 1). The seta is the secondary seta.

In the polychaeten Larvengruppe, secondary tubercles appear between the tubercles of (Dae) and (DLai) which I name (ad 2), and sometimes $(\operatorname{ad} 2)$ is divided into anterior and posterior ones, ( $\mathrm{ad} 2 \mathrm{a}$ ) and (ad 2p). Further, an additional transverse row of the tubercles appears in the course of larval growth, and they are situated before the tubercles, (Dai) and (Dae). I name these tubercles as (ad 3) and (ad 4).

Sternal region: In this part, sometimes a secondary tubercle appears. I name it as (as 2). This tubercle is situated between the tubercles (P) and (PS).

\section{Types OF THE TUBERCULAR FORMS OCCURRING IN JAPANESE CHRYSOMELINAE}

\section{Prothorax}

Prothoracic tubercular forms are divided into two large types. These are (D-DL-EP) type, and (D -DL-EPa) and (EPp) type. (Plate 1: $4,7)$ The former type occurs in the species belonging to Chrysolina, Oreina, Polygramma, Phola, Scleophaedon, Gonioctena, Colaphellus, Entomoscelis, Potaninia and Hydrothassa. The latter type occurs in the species belonging to Gastrophysa, Phaedon, Phratora, Mesoplatys, Plagiodera, Chrysomela, Gastrolina, Gastrolinoides and Linaeidea. In the thoracic segments, tubercle (PS) is lacking. Usually, in the sternal region, the tubercle shows (ES-SS).

\section{Meso- and metathorax}

\footnotetext{
* In polychaeten Larvengruppe, I could not examine the change of tubercles on enough material, and so these tubercles are named for convenience.
} 
Meso- and metathoracic tubercular forms are divided into 2 types. These are (DL) type, and (DLai), (DLpi) and (DLe) type. (Plate 1:5,8) The species of Gastrophysa, Phaedon, Phratora, Mesoplatys, Plagiodera, Chrysomela, Gastrolina, Gastrolinoides, Linaeidea, Hydrothassa and Prasocuris belong to the former type. The species of Chrysolina, Phola, Scleophaedon, Gonioctena, Colaphellus, Entomoscelis and Potaninia belong to the latter type. The tubercles of the sternal region consist of 2 tubercles, (ES) and (SS). (PS) is lacking.

\section{Abdomen}

Abdominal tubercular forms are also divided into 2 types. These are (DL) type, and (DLai), (DLpi), (DLae) and (DLpe) type. (Plate 1: 1,6). All of the species belonging to (DL) type in meso- and metathorax show (DL) type in abdomen. Also, all the species belonging to (DLai), (DLpi) and (DLe) type in meso- and metathorax show (DLai), (DLae), (DLpi) and (DLpe) type in abdomen. The tubercles of sternal region consist of 2 tubercles, (FS) and (SS-PS).

Thus, the principal tubercular forms of this subfamily are largeiy divided into two large types. The first type is (D-DL-EPa) and (EPp) type in prothorax, and (DL) type in meso- and metathorax and abdomen.* The second type is (D-DL-EP) type in prothorax, (DLai), (DLpi) and (DLe) type in meso- and metathorax, and (DLai), (DLpi), (DLLae) and (DĹpe) type in abdomen. The former group has 9 pairs of opening of eversible glands oñ (DL) of meso- and metathorax and abdomen. The latter group has not the above mentioned eversible glands. I name the former group as the Gianduiferous group and the latter one as the Nonglanduliferous groutp. The glanduliferous group corresponds to Hennig's oligochaeten Larvengruppe, and the nonglanduliferous group to polychaeten Larvengrupte.

Between the larvae of the glanduliferous and nonglanduliferous groups, tubercular forms are exceedingly different from each other. The tubercular forms of the nonglanduliferous group are very complicated, in a rough appearance. But it is possible to recognize these homologous relations based on the tubercles of subapical abdominal segments and on the musculature of dorso-lateral part. (Plate 1: 10-15) In subapical segments, all of the tergal tubercles have a tendency to fuse together. Further, in the seventh or the eighth (sometimes the sixth) abdominal segment the tubercles consist of a large tergal plate. These tendencies are very suggestive of the homologous relations between the glanduliferous and nonglanduliferous groups. Moreover, the attached points of a muscle, noto-coxal muscle, also indicate the border between the dorsal and dorso-lateral parts.

* In Prasocuris and Hydrothassa, tubercular forms show (D-DL-EP) in prothorax and (DL) in meso- and metathorax and abdomen. 


\section{Changes of the LARVAL TUbercles and SETAE IN THE COURSE OF THE LARVAL GROWTH}

The larval tubercles and setae of Chrysomelinae show many kinds of changes in the course of the growth. As to the setae, the secondary setae increase in numbers and relative length, and also the primary setae reduce in relative length in the course of the growth. As to the tubercles, the secondary tubercles appear in most species, and these tubercles increase in size and numbers in the course of the growth. Within the same species or among the same groups some tubercles disappear in the last larval instar. I believe that it is very important to recognize dynamically these morphologies through the changes from the first larval instar to the last one. (Tabs. 1,2)

Table 1. Disappearance of the tubercles in the course of larval growth.

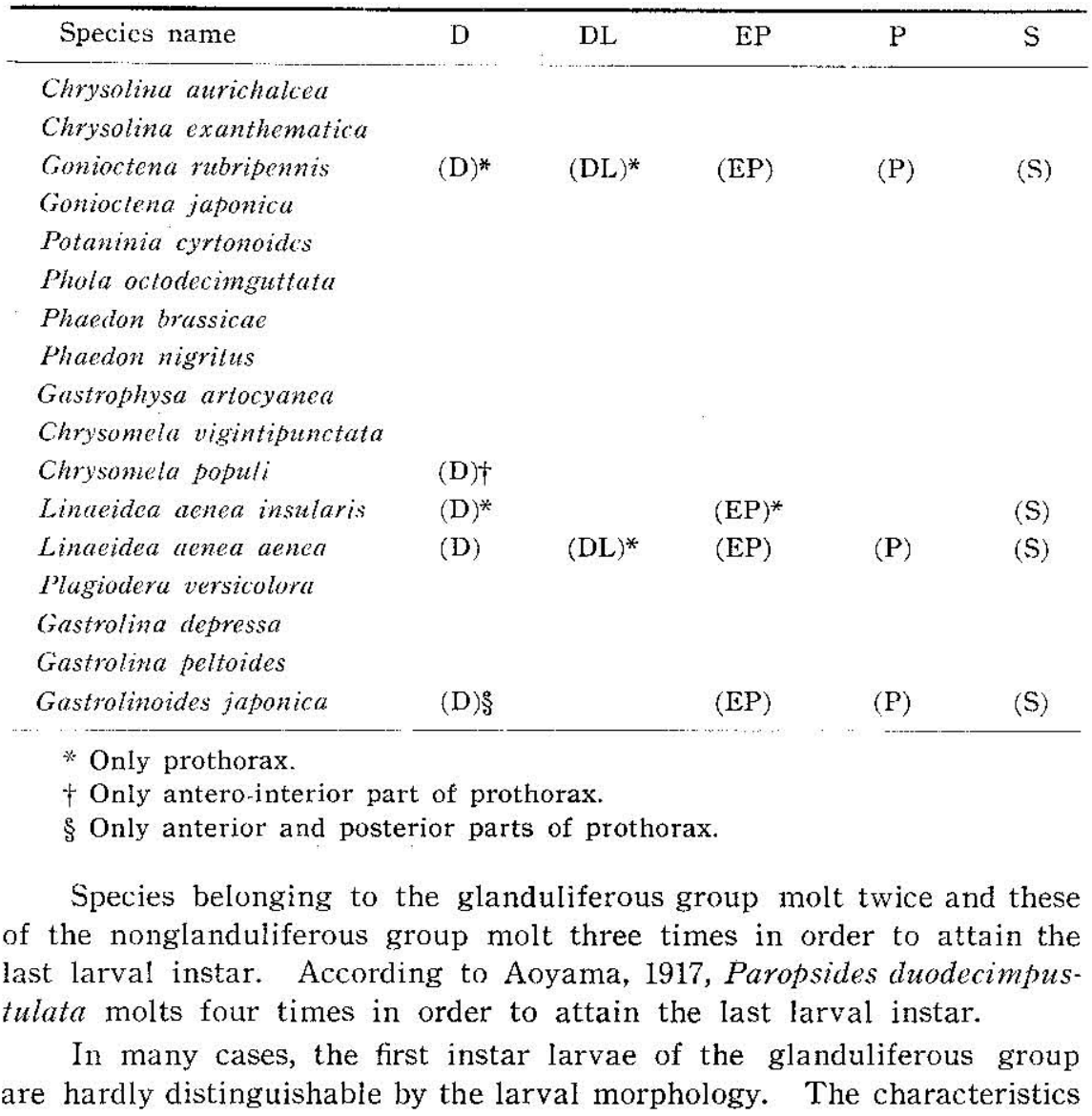


Table 2. Secondary tubercles.

\begin{tabular}{|c|c|c|c|c|}
\hline \multirow{2}{*}{ Species name } & \multirow{2}{*}{\multicolumn{2}{|c|}{$\overbrace{\text { dorsal }}^{\text {Meso- and metathorax }} \underbrace{}_{\text {sternal }}$}} & \multicolumn{2}{|c|}{ Abdomen } \\
\hline & & & dorsal & sternal \\
\hline \multicolumn{5}{|l|}{ Chrysolina aurichalcca } \\
\hline \multicolumn{5}{|l|}{ Chrysolina exanthematica } \\
\hline \multicolumn{5}{|l|}{ Gonioctena rubripennis } \\
\hline \multicolumn{5}{|l|}{ Gonioctena japonica } \\
\hline Potaninia cyrtonoides & $\operatorname{ad} 1, \operatorname{ad} 2, \operatorname{ad} 3$ & & & as 2 \\
\hline Phola octodecimguttala & $?$ & $?$ & $?$ & as 2 ? \\
\hline Phaedon brassicae & & & & as 1 \\
\hline Phaedon nigritus & & & & as 1 \\
\hline Gastrophysa atrocyanea & ad 1 & & ad 1 & as 1 \\
\hline \multicolumn{5}{|l|}{ Chrysomela vigintipunctata } \\
\hline \multicolumn{5}{|l|}{ Chrysomela populi } \\
\hline Linaeidea aenea insulari & & & & as 1 \\
\hline \multicolumn{5}{|l|}{ Linaeidea aenea aenea } \\
\hline Playiodera versicolora & & & ad 1 & as 1 \\
\hline Gastrolina depressa & & & & as 1 \\
\hline Gastrolina peltoides & & & & as 1 \\
\hline Gastrolinoides japonica & & & & as 1 \\
\hline
\end{tabular}

of the species or of the more higher taxonomic groups grandually appear in the course of growth. (Tab. 3)

In the second instar larvae of Gastrolina, Gastrolinoides and Chrysomela, secondary tubercles (as 1) gradually appear in the sternal region. In the third instar, the larvae of Gastrolina depressa, G. peltoides and Chrysomela spp. (such as Chrysomela populi, C. vigintipunctata) do not show so much changes of tubercles during the instar. In the larvae of Gastrolinoides japonica the tubercles of epipleural, pleural and sternal tubercles gradually disappear.

On the other hand, in the second instar larvae of Linaeidea, secondary tubercles (as 1) appear in the sternal region. In the last instar larvae, the tubercles of the sternal region gradually disappear in the course of the growth. In the larvae of linaeidea aenea insularis, except for the glanduliferous tubercles (DL) Iocating on meso- and metathorax and abdomen, dorsal tubercles disappear.

In the second instar larvae of Plagiodera versicolora secondary dorsal tubercles (ad 1) and secondary sternal tubercles (as 1) gradually appear. In the second instar larvae of Phaedon brassicae and Gastrophysa atrocyanea, secondary tubercles appear in the sternal and dorsal parts, but do not show remarkable changes in the third instar.

Considering the above mentioned changes in the course of the larval 
Table 3. Change of tubercles in the course of
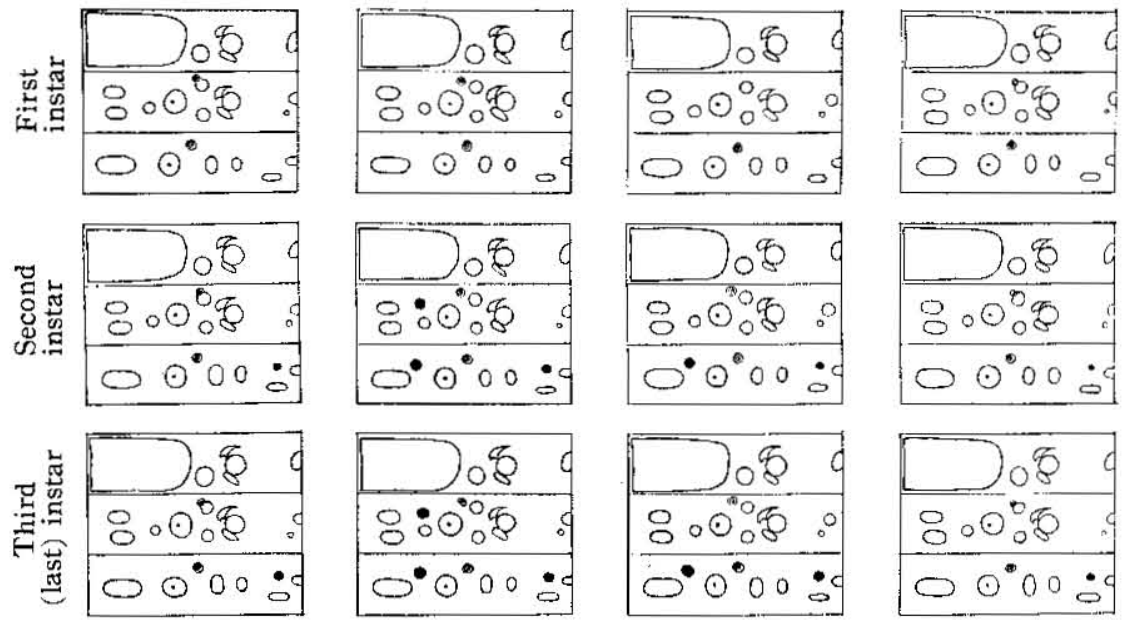

Phaedon brassicae Gastrophysa atrocyanc Baly Motschulsky

(Laichart)

(such as populi)

growth, the following conclusion may be derived. In the second instar, general tubercular forms of Chrysomela, Gastrolina and Gastrolinoides are almost identical, but in the third instar, larvae of Chrysomela and Gastrolina do not show remarkable changes in the tubercular forms, but in the larvae of Gastrolinoides tubercles of epipleural, pleural and sternal regions disappear in the course of larval growth. These disappearances produce the characters which may distinguish the species from the others. In the second instar, the primary tubercles of Linaeidea aenea aenea are hardly distinguishable from each other, but in the third instar, sternal, pleural, epipleural and some parts of tergal tubercles gradually disappear and the grade of the disappearance of tubercles produces distinguishable characters of some subspecies. Among the rather relative taxa of Chrysomelinae, it will be pointed out that between the tubercular forms of these larvae and changes of tubercles in the course of the growth, the parallel relations are recognizable. It might be said that tubercular forms of the last larval instar show parallel relations to the gradational differences in the larval growth. Between the second larval instar of Plagiodera, Chrysomela and Gastrolina the same relation is recognized.

Although in the nonglanduliferous group the changes of tubercles are extreme and interesting, the beetles belonging to this group are very scarce in Japan. It is almost impossible to recognize an outline of this group. But I think that the following data suggest the above mentioned relations. (Tab. 4) 
larval growth (Glanduliferous group)
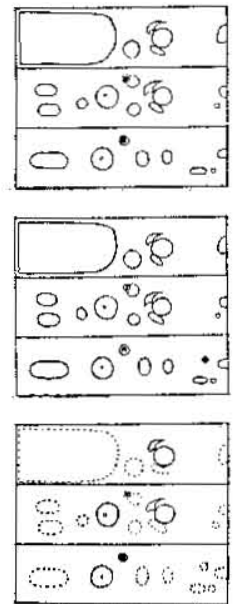

Linaeidea aenea Linn. (Japanese race)
Primary tucercles

Secondary tubercles

Tubercles which disappear in the course of larval growth
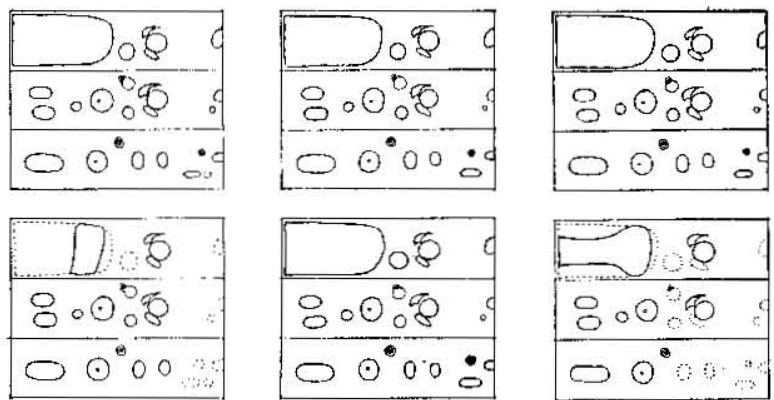

Linaeidea aenea insularis (Chûjo)

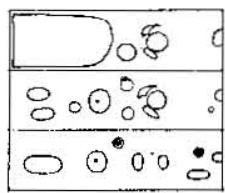

Gastrolina spp. (such as depressa)

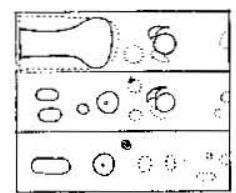

Gastrolinoides japonica (Harold)

In the first larval instar, tubercular forms of Gonioctena (Brachy. phytodecta) rubripennis and Potaninia cyrtonoides are very similar. But in the larvae of $P$. cyrtonoides, secondary tubercles appear in the course of development. These are (ad 2), (ad 3) and (ad 4) in mesoand metathorax and (as 2) in abdomen. These tubercles always appear on the same places. In addition to these, many other seconday tubercles appear but the positions of these tubercles are too irregular to give name upon them. In $G$. rubripennis secondary tubercles also appear in the course of growth, but all of the tubercles appear at random. But in the fourth (the last) larval instar another type of change is observed, that is the disappearance of the sternal, pleural and epipleural tubercles. The larva of Phola octodecimguttata shows an interesting tubercular form. I could not examine the first instar larva but examined many of the larvae of various instars. In Table 4, the black painted tubercles of this species are considered as the secondary tubercles judging by the tubercular forms of younger specimens and these of variations. It is suggested that the primary tubercles of Phola octodecimguttata have many similarities to $P$. cyrtonoides. ${ }^{*}$ Thus, it will be recoginized that the tubercular froms of these three species show a series of parallel relations to the gradational differences of the larval growth, as in the

* The tubercles of Entomoscelis adonidis described by Hennig (1928) consist of 3 rows of tubercles. I have no opinion about these 3 rows of tubercles. It must be noticed, however, that the tubercular forms are very similar between the tubercular forms of Phola octodecimguttata and Entomoscelis adonidis. 
glanduliferous group.

On the setae, these changes are also traced. Between the generic group Phaedon and generic group Chrysomela $\dagger$ belonging to the glanduliferous group, one of the characteristics is the relative length of setae. In the first larval instar, the larval setae of both groups are very long compared with the length of body. In the group of Phaedon, the reduction ratio of relative length of the setae in the course of growth is smaller. But, in the group of Chrysomela the ratio is large. Thus, the relative length of the larval setae produces the characteristics in the course of larval growth.

As I already pointed out in Chapter IV, the changes of setal number of the nonglanduliferous group also appear in the course of larval growth, but I think these changes can be explained as a similar case.

Table 4. Change of tubercules in the course of larval growth (Nonglanduliferous group).
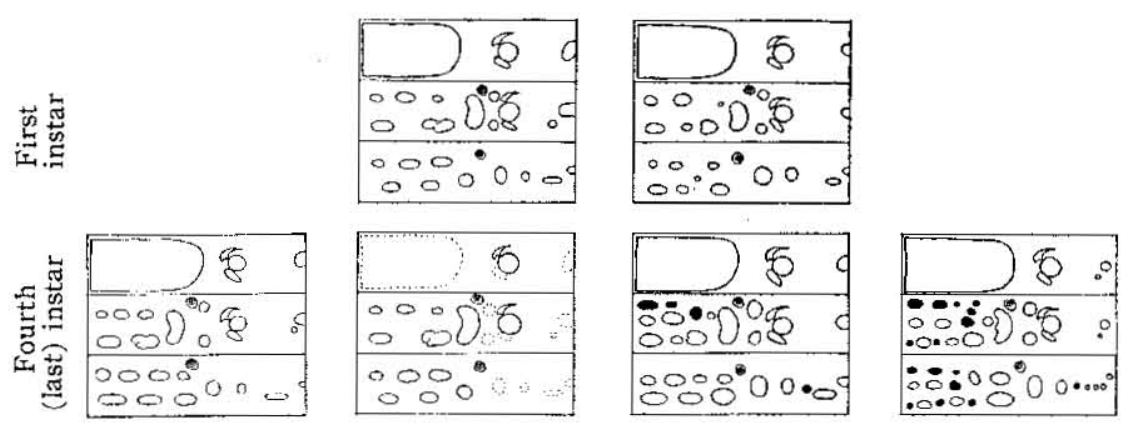

Gonioctena (Gonioctena) Gonioctena (Bra- Potaninia cyrtonoides spp. (such as rufipes viminalis) (after

Hennig, 1938) chyphylodecta) (Jacoby) rubripennis

Phola octodecim. guttata (Fabr.)*

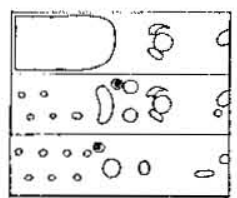

Chrysolina spp. (such as $C$. aurichalcea)

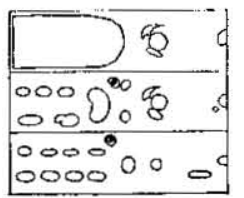

Golaphellus sophiae Schall (after Hennig, 1938)

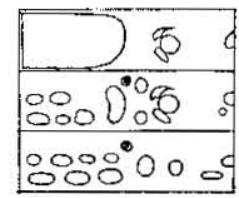

Scleophaedon car niolicus Germ. (after Hennig, 1938)

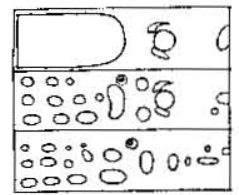

Entomoscelis ado nidis Fall. (after Hennig, 1938)

$\dagger$ cf. Chapter ViII.

* I could not examine the first instar larvae of this species. The black painted tubercles of the species are supposed as the secondary tubercles. 


\section{TAXONOMIC NOTE}

\section{Historical review}

The first attempt to divide the subfamily into tribes was done by Reitter (1912), based on the species of central Europe. He treated this subfamily as a tribe, Chrysomelini, and divided it into four subtribes, namcly Timarchina, Chrysomelina, Prasocurina and Entomoscelina.

Weise (1915 et '16) divided this subfamily into eight tribes, namely Zygogrammini, Chrysomeini, Phaedonini, Dicranosternini, Paropsini, Phyllodectini, Phyllocharini and Timarchini. Until today, his system has been followed by most entomologists, being partly corrected by Chen and Bechyně.

On the other hand, Paterson (1931) criticized Weise's system hased on the knowledge of comparative morphology of eariy stages collected in England. He divided the subfamily into four groups. They are Chrysomelina, Phaedonia, Prasocurina and Timarchina. He concluded that Phyllodecta (=Phratora) is very similar to Phaedon, Gasirvidea (=Gastrophysa) and so on, and also treated Prasocurina as an independent group.

Hennig (1938) also did research on the larval morphologies of Chrysomelinae, and contributed toward the addition of knowledges of eariy stages, especiaily of the nongianduliferous group. He criticized Weise's Phaedonini and Phyllodectini. That is: Phyllodecta ( Phratora) and Phytodecta (=Gonioctena) belong to Phyllodectini but these two genera have much morphological differences, and Phraiora has many similarities to Phaedonini, such as Gastrophysa, Phaedon and so on, while Scleophaedon and Collaphellus belong to Phaedonini but these two genera have many similarities to Phytodecta (=Gonioctena). Hc settled a group consisting of Phytodecta (=Gonioctena), Scleophaedon, Entomoscelis and Colaphus ( $=$ Colaphellus). This is his second group. His system was about the same as Paterson's, but he did not recognize the independence of Prasocurina but included it with Phaedonia.

\section{Phylogenic considerations based on early stages}

According to the larval and pupal morphology, beetles of the subfamily are divided into two large groups, namely glanduliferous group and nonglanduliferous group. Glanduliferous group is characterized by 9 pairs of eversible glands located on (DL) of meso- and metathorax and abdomen and 2 pairs of egg bursters located on (Dpe) of meso- and metathorax in the larval stage, and round apex of the ninth abdominal segment in the pupal stage. All the larvae belonging to this group molt twice in order to attain the last larval instar. Nonglanduliferous group is characterized by the absence of these eversible glands and 3 pairs of egg bursters located on (DLpi) of meso- and metathorax and on (DLp) 
of the first abdominal segment in the larval stage, and apex of the ninth abdominal segment with a pair of or single projection in the pupal stage. All the larvae belonging to the group molt three times in order to attain the last larval instar.

Based on my examinations and descriptions made by Paterson, Hennig and Chen, the following genera are included in the glanduliferous group. These are Phaedon, Gastrophysa, Phratora, Mesoplatys, Plagiodera, Chrysomela, Linaeidea, Gastrolina, Gastrolinoides, Prasocuris and Hydrothassa.

In the group, Phaedon, Gastrophysa, Phratora and Mesoplatys are regarded as to form a similar taxonomic group. Compared with the other genera of the glanduliferous group, these 4 genera are characterized by generally thiner pupal skin, rather scarce but rather long and strong setae, the seventh abdominal segment without any lateral tuberculation in the pupal stage, unexcavated tarsi at the base, and rather scarce and short setae in the larval stage. I name this group as generic group Phaedon.

Plagiodera, Chrysomela, Linaeidea, Gastrolina and Gastrolinoides seem to make a similar taxonomic group. In the glanduliferous group these 4 genera are characterized by the following characters: Generally thicker pupal skin, extremely scarce and short setae, distinct lateral tuberculation of the seventh abdominal segment in the pupal stage, excavated tarsi at the base, and rather scarce and short setae in the larval stage. I name this group as generic group Chrysomela.

Judging by the descriptions done by Paterson and Hennig, I think Prasocuris and Hydrothassa are forming a very similar taxonomic group. Generally in the glanduliferous group, the group may be characterized by the tubercular type, (D-DL-EP) in prothorax and (D) in meso- and metathorax in the larval stage. I name the group as generic group Prasocuris.

Judging by the tubercular form and biology, these 3 groups are forming a rather similar taxonomic group, but the relationship between the generic groups Phaedon and Chrysomela is much closer than that between the generic groups Paedon and Prasocuris. Therefore, the generic group Prasocuris may be regarded as a somewhat specialized taxonomic group. These 3 groups, glanduliferous group, may correspond to Hennig's oligochaeten Larvengruppe. The larvae of the generic groups Chrysomela and Prasocuris pupate on the food plant, while these of the generic group Phaedon pupate in the ground as the larvae of nonglanduliferous group. It is pointed out that according to the method of pupation general morphologies of pupae show the adaptive feature. That is, the pupae of the former type show that the pupal skin is very thick and the dorso-lateral part of the seventh abdominal segment is strongly projected. The pupae of the latter type 
show that the pupal skin is very thin and soft and the dorso-lateral part of the scventh abdominal segment is not projected. When the beetles pupate on the host plant, they put the apex of the larvae on the leaf, molt the skin of the last instar larvae and hook up the skin of the last instar larvae by the lateral projections and hang. A pair of lateral projections may be said to be an adaptive feature. The thick and strong skin of the surface will protect the pupae in many ways, being more severely influenced by surroundings than in the ground. Similarly it may be said to be an adaptative feature.

According to Weise's system $\left(1915^{-}{ }^{\prime} 16\right)$, the above mentioned 9 genera were included in Phaedonini, except for Phratora, with Scleophaedon and Colaphellus, but Scleophaedon and Colaphellus are very different from 9 genera by the absence of 9 pairs of glanduliferous tubercles and general tubercular form, and should not be included in this group but should be included in the nonglanduliferous group. Phratora was contained in Phyllodectini with Gonioctena but Gonioctena should belong to the glanduliferous group and differs from Phratora in various points, and this is also supported by biological points of view.

On the other hand, the following genera are included in the nonglanduliferous group. These are Chrysolina, Polygramma, Oreina, Gonioctena, Colaphellus, Scleophaedon, Entomoscelis, Potaninia and Phola. Until today, unfortunately, it is hardly said that sufficient studies were performed on many genera which belong to the nonglanduliferous group. I could not sufficiently recognize these morphological outlines of early stages of the Chrysomelids belonging to the group, because of the poorly represented genera or species in Japan.

In the group, Chrysolina, Polygramma and Oreina may be regarded as belonging to the similar taxonomic genera. In the group, these 3 genera are characterized by a single projected apex of the ninth abdominal segment in the pupal stage, and much convex body and very small tubercles (sometimes not appearing) in the larval stage. I name the group as generic group Chrysolina. The group may correspond to Chrysomelini in Weise's system.

Also, Gonioctena, Scleophaedon and Colaphellus may belong to a closely related taxonomic group. In the nonglanduliferous group, these 3 genera are characterized by the apex of the ninth abdominal segment with a pair of projections in the pupal stage, less convex body, comparatively larger size of tubercles, and dorsal and doso-lateral tubercles consisting of 2 transverse rows in the larval stage. I name the group as generic group Gonioctena.

The remaining 3 genera, Potaninia, Entomoscelis and Phola are very specialized genera in the nonglanduliferous group.

According to Weise's system, Timarcha, Entomoscelis and Potaninia belong to Timarchini. But Chen (1936) divided Timarchini into 2 
Table 5. Table of classification of

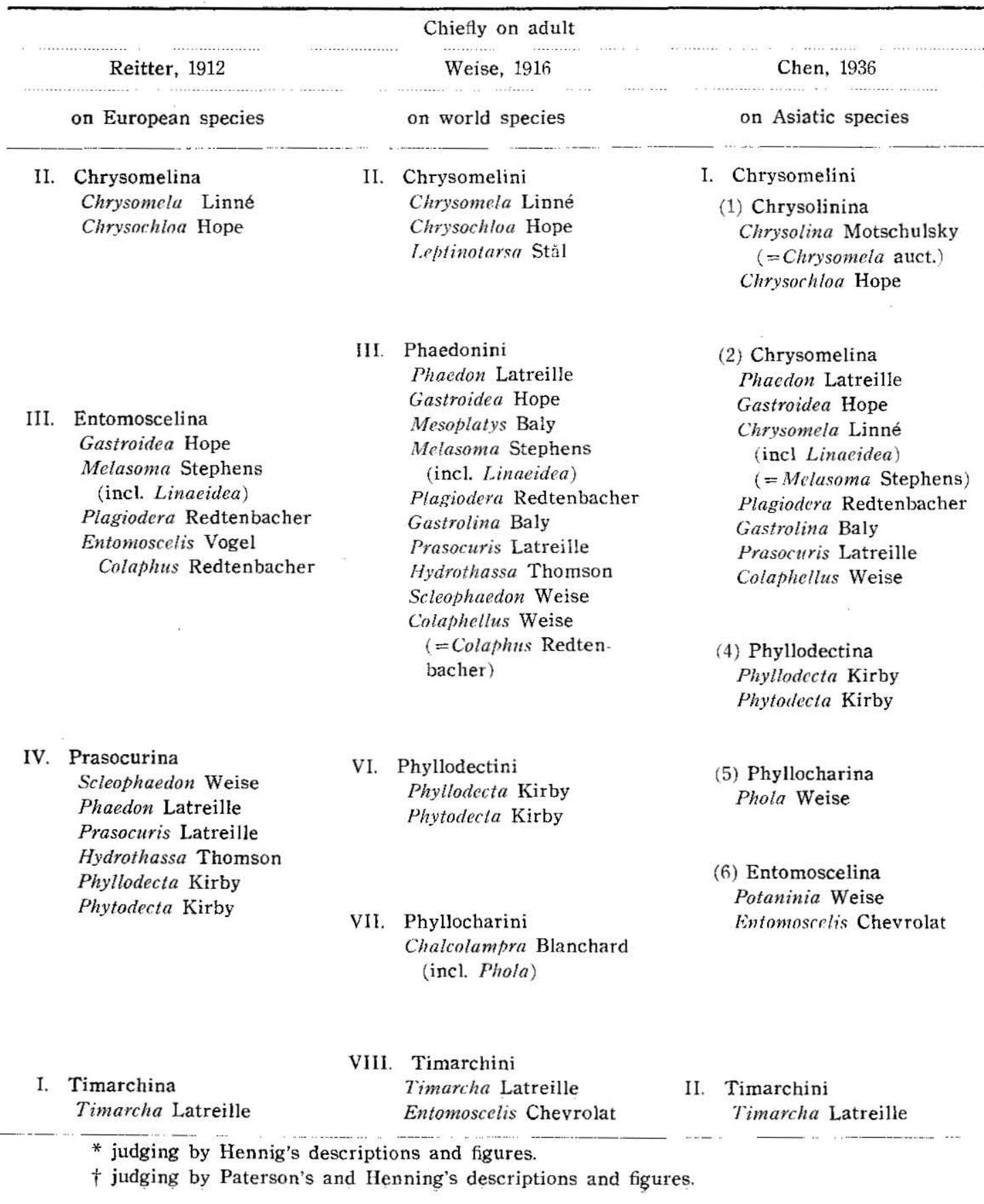


Chrysomelinae by authors.

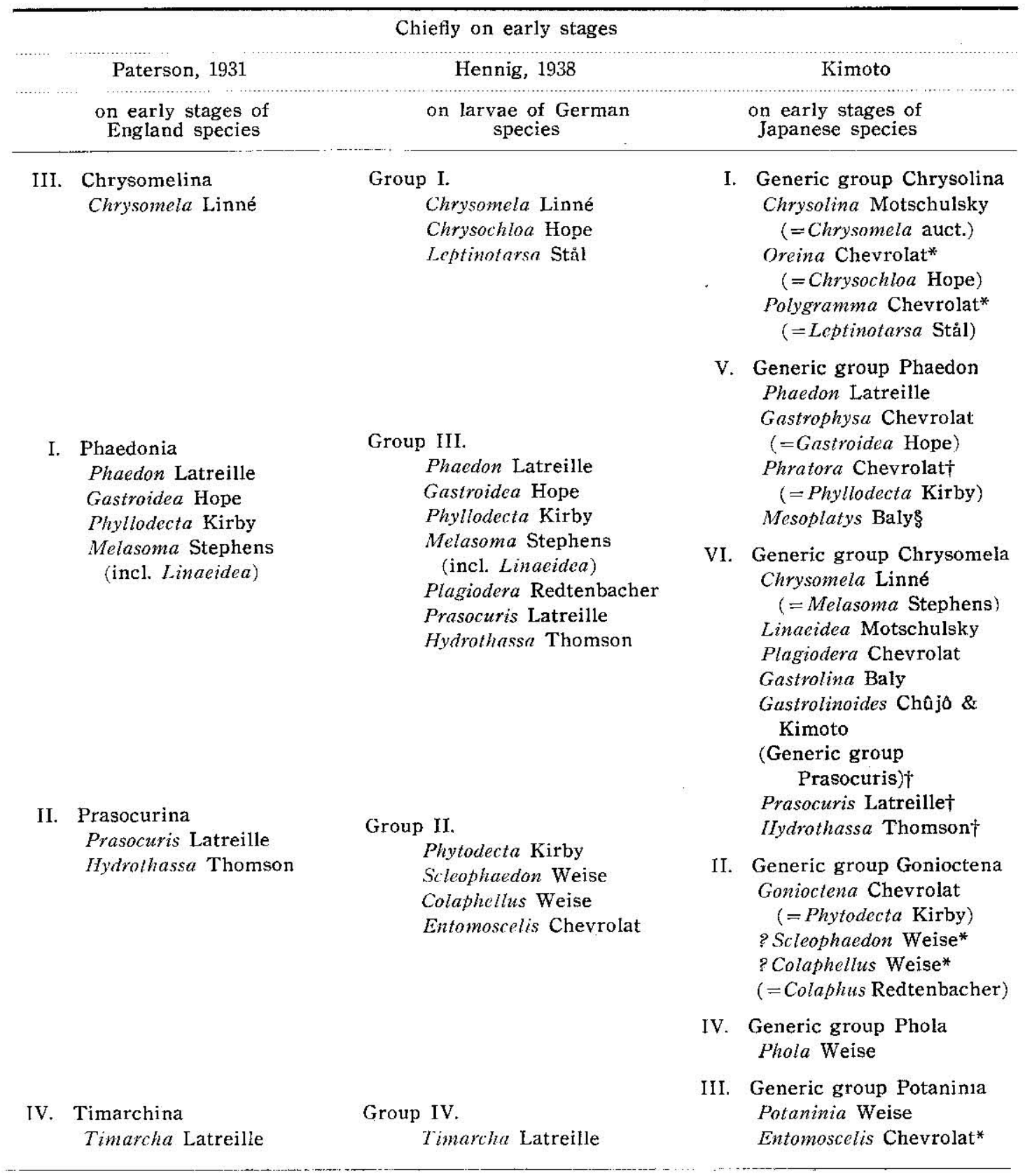

§̧ judging by Chen's description and figure. 
groups and recognized an independent tribe Entomoscelini. Most of the genera of Timarchini of old sense were included in Entomoscelini and Timarcha and some of genera remained in Timarchini.*

On the early stages of Chen's Entomoscelini, there is only one report which includes the larval description of Entomoscelis adonidis done by Hennig, and larval and pupal descriptions of Potaninia cyrtonoides given by me in this paper. Therefore, I could not satisfactorily recognize the morphological outline of this group. Moreover, there is a trouble problem, for these characteristic 3 rows of tubercles vary remarkably in size and number in the course of larval growth. In the last instar larvae of Entomoscelis adonidis described by Hennig, tubercles consist of 3 transverse rows. On the other hand, in the last instar larvae of Potaninia cyrtonoides, tubercles of dorsal and dorso-lateral regions of meso- and metathorax also consist of 3 transverse rows. But in these rows, the first one does not appear in the first instar larvae and these gradually appear with the other secondary tubercles in the course of larval growth, and at last in the fourth (the last) instar larvae these row grow very conspicuously. It seems to be difficult to recoginize the homology of tubercles of Entomoscelis adonidis satisfactorily without the study of the first instar larvae, but it may be a very characteristic feature that the tubercles of the last instar larvae consist of 3 transverse rows. I name the group as generic group Potaninia.

The tubercular form of the first instar larvae of $P$. cyrtonoides shows much similarities to the generic group Gonioctena and this species has a pair of projections on the apex of the ninth abdominal segment in the pupal stage. It may be said that these features suggest the systematic relationship between these 2 groups, and the generic group Potaninia is a highly specialized group which may be derived from the generic group Gonioctena, especially like Gonioctena (Brachyphytodecta) rubripennis.

Until today, studies on the morphologies of the early stages of Phyllocharini (in Weise's system) have not been done and, perhaps, all that is known is what I report on Phola octodecimguttata in this paper, and I could not recognize the morphological outline of this group. The tubercular form of the larvae shows strong resemblances to the last instar larvae of the generic group Potaninia and this generic group may be characterized by its rather scarce club-shaped setae in the last instar larvae. I name the group as generic group Phola.

In the nonglanduliferous group, the generic groups Potaninia and Phola are much resembling taxonomic groups. Also these 2 groups suggest the systematic relationship to the generic group Gonioctena.

\footnotetext{
* Bechynĕ (1918) treated this tribe Timarchini as an independent subfamily Timarçhinae,
} 


\section{LITERATURI:*}

Bechyně, J., 1948. Contribution à la connaissance sur genre Timarcha Latr. 12: Etudes Phyllogénétiques et zoogéographiques. Acta Musei Nat. Prage 4B (2): $1-62$.

Bbving, A. G., 1929. Beetle larvae of subfamily Galerucinae. Proc. United States Nat. Mus. 75: 1-48, pls. 1-5.

Chen, S. H., 1934. Sur la position systematique de genre Timarcea Latr. Bull. Soc. ent. Fr. 1934 : 35-39.

Chen, S. H., 1934. Sur une larve de Chrysomelidae du Mozanbique (Mesoplatys ochroptera). Bull. Soc. ent. Fr., 39: 270-271.

Chen, S. H., 193j. Recherches sur les Chrysomelinae de la Chine et de Tonkin (Morphologie de larves). (Thèse, Fac. Sci. Univ. Paris) 104 pp. (ref. pp. 11-22).

Chen, S. H., 1936 Catalogue de Chrysomelinae de la Chine, de l'Indochine et du Japon. Not. d'Ent. Chin. 3: 63-102, pl. III.

Fracker, S. B., 1915. The classification of Lepidopterous larvae. Illinois Biol. Monogr. 2 (1): 1-161, pls. 1-10.

Hennig, W., 1938. Übersicht über die wichtigsten deutschen Chrysomelinen. Arb. phys. angew. Ent. $5(2): 85-136$, pls. I-II.

Kimoto, S., 1957. Biological studies on earlier stages of Japanese Chrysomelinae. Sci. Bull. Fac. Agric. Kyushu Univ., Fukuoka 16 (1): 41-57.

Lipp, H., 1935. Die Lebensweise von Melasoma aenea (L.) in der Mark. Deutsch. Ent. Zeit. 1935: 1-64, pl. I.

Maulik, S., 1926. Fauna Brit. Ind., Col. Chrysomelidae (Chrysomelinae \& Halticinae).

Paterson, N. F., 1930. The bionomics and morphology of the early stages of Paraphaedon tumidulus Germ. Proc. Zool. Soc. London 1930: 627-676, pls, IIV.

Paterson, N. F., 1931. The biomonics and morphology of certain Chrysomelidae. Proc. Zool. Soc. London 1931: 879-949, pls. I-III.

Sanderson, E. D., 1902. Notes upon the structure and classification of Chrysomelid larvae. Proc. Ent. Soc. Wash. 5: 21-31.

Weise, J., 1916. Coleop. Cat. Pars 68. Chrysomelinae.

* Literature concerning the bionomics should be refered to ones cited in my previous paper (1957). 


\section{Explanation of Plate 1}

1. Dorsal and dorso-lateral regions, showing meso- and metathorax of (DLai), (DLpi), (DLae) and (DLpe) type.

2. Epipleural, pleural and sternal regions. Thorax.

3. Ibid. Abdomen.

4. Dorsal and dorso-lateral regions. Prothorax of (D-DL-EPa) and (EPp) type.

5. Ibid. Meso- and metathorax of (DL) type.

6. Ibid. Abdomen of (DL) type.

7. Ibid. Prothorax of (D-DL-EP) type.

8. Ibid, Meso- and metathorax of (DLai), (DLpi) and (DLe) type.

9. Secondary tubercles. Dorsal, dorso-lateral and sternal regions.

10. Seventh and eighth abdominal segments of Glanduliferous group.

11. Sixth and seventh abdominal segments of Gonioctena (Gonioctena) spp.

12. Sixth and seventh abdominal segments of Gonioctena (Brachyphytodecta) rubripennis.

13. Seventh and eighth abdominal segments of Potaninia cyrtonoides.

14. Seventh and eighth abdominal segments of Entomoscelis adonidis. (Based on the description made by Hennig).

15. Fifth and sixth abdominal segments of Phola oclodecimguttata. 

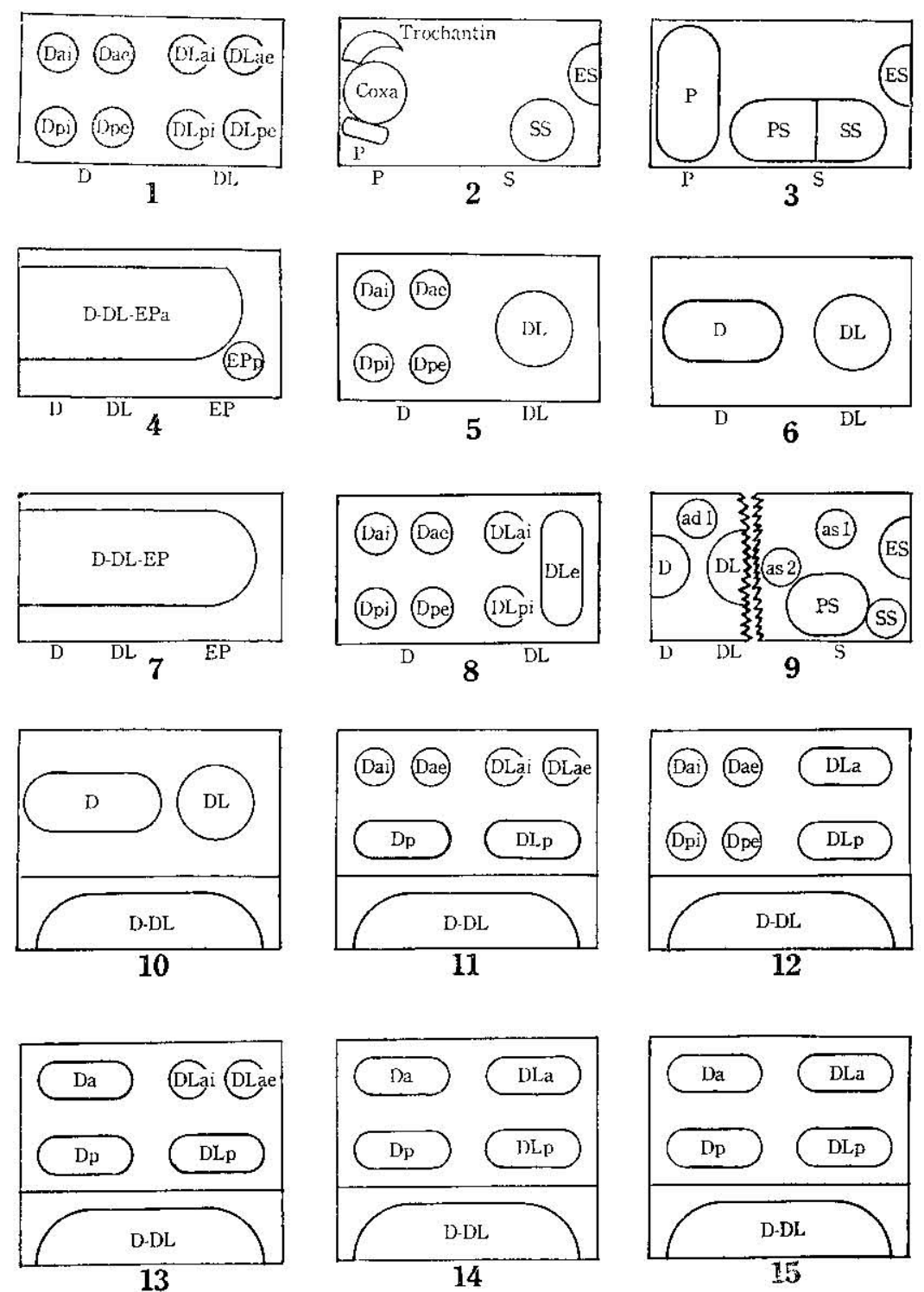

A phylogenic consideration of Chrysomelinae 